\title{
Effect of imbalance between energy and nitrogen supplies on microbial protein synthesis in growing double-muscled Belgian Blue bulls
}

D. Valkeners, Y. Beckers, F. Piron and A. Théwis

Gembloux Agricultural University, Passage des Déportés 2, 5030 Gembloux, Belgium, Email: valkeners.d@fsagx.ac.be

Introduction Balancing the supply of nitrogen and energy-yielding substrates to rumen micro-organisms was proposed as a mechanism to maximise the capture of rumen degradable nitrogen (RDN) and to optimise microbial growth rate and efficiency. The objective of this study was to examine the effect of various time periods of imbalance between nitrogen and energy supplies for the rumen micro-organisms on the microbial protein synthesis (SPM) in growing double-muscled Belgian Blue bulls. This was realised by giving the same feedstuffs according to different meal patterns, which is one of the most robust test of the 'synchrony' hypothesis (Dewhurst et al., 2000).

Materials and methods Six double-muscled Belgian Blue bulls initially weighing $345 \pm 16 \mathrm{~kg}$ and fitted with a ruminal cannula and a T-type cannula at the proximal duodenum were used in the study. The bulls received the same diet according to three different feeding patterns, so that three different time periods of imbalance between energy and nitrogen supplies for the rumen microbes were created. The diet gave $97.5 \mathrm{~g}$ of intestinal digestible proteins (DVE) and $1842 \mathrm{kcal}$ of NEF per kilogram of DMI according to the Dutch system. Feed was provided twice a day in equal amounts at 0830 and 2030 at an intake level of $85 \mathrm{~g} \mathrm{DM} / \mathrm{kg}^{.75}$. The first feeding pattern of the diet (0h) consisted in giving at each meal all the feed ingredients, which resulted in a RDN:FOM ratio equal to $24 \mathrm{~g} / \mathrm{kg}$ of fermentable organic matter (FOM). Therefore, the energy and nitrogen-yielding substrates to the rumen micro-organisms were considered synchronised. The second pattern (12h) consisted in giving at the morning meal the feed ingredients, which primarily provided energy for the rumen microbes (ENE) and at the evening meal the feed ingredients, which primarily provided nitrogen (PRO). An imbalance of a duration of $12 \mathrm{~h}$ between the energy and nitrogen supplies for the rumen microbes was thus experimentally created. The RDN:FOM ratios amounted to 19 and $29 \mathrm{~g} / \mathrm{kg}$, for ENE and PRO respectively. However, the RDN:FOM ratio per day was $24 \mathrm{~g} / \mathrm{kg}$ and the same feedstuffs were ingested. The last feeding pattern ( $24 \mathrm{~h}$ ) consisted in increasing the time period of imbalance to $24 \mathrm{~h}$ by feeding alternately ENE at the two meals of a day and PRO at the two meals of the day after. The RDN:FOM ratio per $48 \mathrm{~h}$ was also $24 \mathrm{~g} / \mathrm{kg}$ and the same amounts of each feed ingredients were ingested compared $0 \mathrm{~h}$ and $12 \mathrm{~h}$. The bulls were allocated to three treatment periods in two juxtaposed $3 \times 3$ Latin squares. Rumen fermentation was monitored by $\mathrm{pH}$ and ammonia concentration. Total digesta and microbial protein flows to the proximal duodenum were measured using chromic oxide as an indigestible flow marker and purines as a microbial marker.

Results No significant differences in rumen $\mathrm{pH}$ were seen between the different feeding patterns of the diet. On the other hand, the ruminal ammonia concentration was highly influenced by the nature of the feed ingredients ingested (ENE, PRO or both) and attested the existence of periods of excess and deficiency in $\mathrm{N}$ supply. The period of time that rumen ammonia concentration was below $5 \mathrm{mg} / \mathrm{dl}$ depended on the meal ingested and lasted on average, respectively for ENE, PRO and both

Table 1 Nitrogen intake, nitrogen components flowing to the duodenum and efficiency of microbial protein synthesis (ESPM).

\begin{tabular}{lccccc}
\hline & Oh & $\mathbf{1 2 h}$ & $\mathbf{2 4 h}$ & SEM & p \\
\hline N intake (g/d) & 170.1 & 173.8 & 172.0 & 1.2 & 0.17 \\
Duodenal flow $(\mathrm{g} / \mathrm{d})$ : & & & & & \\
- Total N & 172.8 & 181.3 & 179.6 & 5.6 & 0.55 \\
- Non NH NH $_{3}$ (NAN) & 168.5 & 176.9 & 174.8 & 5.3 & 0.54 \\
- Microbial-N & 70.1 & 73.6 & 72.6 & 2.8 & 0.69 \\
Microbial-N/ NAN (\%) & 41.7 & 41.6 & 41.5 & 0.8 & 0.98 \\
ESPM (g N/kg OMADR) & 26.7 & 31.2 & 29.1 & 2.6 & 0.50 \\
\hline
\end{tabular}
simultaneously, $9 \mathrm{~h}, 0 \mathrm{~h}$ and $6 \mathrm{~h}$ over $12 \mathrm{~h}$. Duodenal dry matter, organic matter and total nitrogen flows (Table 1 ) were similar among the feeding patterns. The duration of imbalance did not affect the organic matter apparently digested in the rumen (OMADR). Microbial nitrogen flows to the duodenum, expressed in $\mathrm{g} / \mathrm{d}$ or in \% Non ammonia-N (NAN), were not significantly different. The efficiencies of rumen microbial protein synthesis (ESPM) were not affected by the duration of imbalance between the energy and nitrogen supplies and reached on average $29 \mathrm{~g}$ N/kg OMADR. These observations supported the hypothesis proposed by Dawson (1999) that the ruminants and their microbes can detect asynchrony in the rate of nutrient supply and have developed mechanisms to overcome or minimise its effects.

Conclusions The introduction of an imbalance of 12 or 24 hours between the energy and nitrogen supplies for the rumen micro-organisms by changing the feeding pattern of the same feedstuffs, did not affect the different nitrogen components flowing to the duodenum or the efficiency of microbial protein synthesis. It would appear that a lack of instantaneous synchronisation between the energy and nitrogen supplied for the rumen microbes is not prejudicial to their growth as long as the nutrient supply is balanced on a 24 or 48 hours basis.

Acknowledgements The research was funded by FRIA, Brussels.

\section{References}

Dewhurst, R.J., Davies, D.R. and Merry, R.J. 2000. Microbial protein supply from the rumen. Animal Feed Science and Technology 85: 1-21

Dawson, J.M. 1999. Variation in nutrient supply and effects on whole body anabolism. In: Proceedings VIIIth International Symposium on Protein Metabolism and Nutrition. (Eds G.E. Lobley, A. White and J.C. MacRae). EAAP Publications, Wageningen, pp.101-126 